\title{
Características da carcaça de vacas de descarte abatidas com diferentes pesos ${ }^{1}$
}

\section{Characteristics of livestock cattle carcasses when slaughtered at different weights}

\author{
Regis Luis Missio ${ }^{2 *}$, João Restle ${ }^{3}$, José Luiz Moletta ${ }^{4}$, Fernando Kuss ${ }^{5}$, José Neuman Miranda Neiva ${ }^{6}$ e Ivan \\ César Furmann Moura ${ }^{7}$
}

\begin{abstract}
RESUMO - Avaliaram-se as características da carcaça de 43 vacas de descarte da raça Purunã com idade média de 68,02 \pm 17,36 meses em diferentes pesos de abate. O delineamento experimental foi inteiramente casualizado e os pesos de abate avaliados foram de 401; 434; 461; 476 e $522 \mathrm{~kg}$. A elevação do peso de abate de 401 para 522 promoveu aumento do peso e rendimento de carcaça quente e fria de 34,$7 ; 36,6 ; 2,1$ e 5,13, respectivamente. A espessura de gordura subcutânea (mm) aumentou linearmente com o avanço do peso de abate, passando de 1,11 para 4,79 mm. A área do Longissimus dorsi expressa em função do peso de carcaça fria variou de forma quadrática com o avanço do peso de abate, com o menor valor estimado para o peso de abate de $440 \mathrm{~kg}$. A quantidade de músculo, gordura e osso aumentaram 300; 330 e $69 \mathrm{~g}$ a cada quilograma a mais no peso de abate, respectivamente. A porção comestível da carcaça aumentou 34,1\% com a elevação do peso de abate de 401 para $522 \mathrm{~kg}$. A elevação do peso de abate representa grande potencial para o aumento da produção de carne no país, dado ao número expressivo de fêmeas de descarte que são abatidas anualmente. No entanto, para o sistema de produção, considerando o atual método de remuneração, o peso de abate de vacas de descarte não deve exceder as exigências mínimas dos frigoríficos, tendo em vista a redução da eficiência alimentar com o avanço da deposição de gordura corporal.
\end{abstract}

Palavras-chave: Rendimento de carcaça. Carne bovina. Gordura de cobertura.

\begin{abstract}
The carcass characteristics of 43 livestock cows of the Purunã breed, with an average age of $68.02 \pm 17.36$ months and of different weights at slaughter, were evaluated. The experimental design was completely randomized, with slaughter weights of 401;434; 461; 476 and $522 \mathrm{~kg}$ being evaluated. The increase in slaughter weight from 401 to $522 \mathrm{~kg}$, promoted a gain in weight and in the hot and cold carcass yield of 34.7; 36.6; 2.1 and 5.13 respectively. The subcutaneous fat thickness $(\mathrm{mm})$ increased linearly with increasing slaughter weight, going from 1.11 to $4.79 \mathrm{~mm}$. The area of the Longissimus dorsi, expressed as a function of the cold-carcass weight varied quadratically with increasing slaughter weight, with the smallest value being estimated for a slaughter weight of $440 \mathrm{~kg}$. The amount of muscle, fat and bone increased by $300 ; 330$ and $69 \mathrm{~g}$ for each additional kilogram of slaughter weight respectively. The edible portion of the carcass increased by $34.1 \%$ with the increase in slaughter weight from 401 to $522 \mathrm{~kg}$. Raising the slaughter weight represents a great potential for increasing meat production in the country, given the significant number of female livestock slaughtered annually. However, based on the production system, and considering the current method of remuneration, the slaughter weight of livestock cows should not exceed the minimum requirements of slaughterhouses, in view of the reduced feed efficiency which accompanies increasing body-fat deposits.
\end{abstract}

Key words: Carcass yield. Beef. Subcutaneous fat thickness.

\footnotetext{
*Autor para correspondência

${ }^{1}$ Recebido para publicação 02/09/2011; aprovado em 24/01/2013

Projeto de pesquisa apoiado pelo Instituto Agronômico do Paraná/IAPAR

${ }^{2}$ Pós-doutorando em Ciência Animal Tropical, Universidade Federal do Tocantins/UFT, Araguaína, Tocantins-TO, Brasil, regisluismissio@ gmail.com

${ }^{3}$ Universidade Federal do Tocantins/UFT, Araguaína, Tocantins-TO, Brasil, jorestle@ terra.com.br

${ }^{4}$ Instituto Agronômico do Paraná, Ibiporã, Paraná-PR, Brasil. moletta @ iapar.com.br

${ }^{5}$ Universidade Tecnológica Federal do Paraná/UTFPR, Dois Vizinhos, Paraná-PR, Brasil, fernando.kuss @ hotmail.com

${ }^{6}$ Universidade Federal do Tocantins/UFT, Araguaína, Tocantins-TO, Brasil, araguaia2007@gmail.com

${ }^{7}$ Programa de Pós-Graduação em Zootecnia/UTFPR, Dois Vizinhos, Paraná-PR, Brasil, ivancesar.moura@bol.com.br
} 


\section{INTRODUÇÃO}

$\mathrm{O}$ abate de vacas de descarte tem atendido parte da demanda de carne bovina pelos consumidores. Tal fato fica evidente pela taxa de abate de fêmeas, que foi de $46 \%$ em 2010, ultrapassando os 50\% em 2006 (ANUALPEC, 2010). Apesar da importância das fêmeas de descarte para o suprimento da demanda de carne pelo mercado consumidor brasileiro e para a renda dos produtores rurais, o preço pago pelos frigoríficos à carcaça de fêmeas de descarte é normalmente $10 \%$ inferior à de novilhos.

A justificativa dada pelos frigoríficos em relação ao menor preço pago pela carcaça de vacas de descarte é vinculada à menor qualidade da carcaça e carne desta categoria em relação aos machos. Todavia, diversos estudos têm destacado a ausência de diferenças marcantes entre carcaças de fêmeas de descarte e novilhos com adequada gordura de acabamento (FERREIRA et al., 2009; PASCOAL et al., 2009), assim como entre a carne destas categorias (CATTELAM et al., 2009; VAZ et al., 2010). Além disso, a menor remuneração proveniente do abate de fêmeas de descarte deixa de fazer sentido, uma vez que, após a separação dos cortes comerciais e desossa, o menor valor pago pela carcaça desta categoria normalmente não é repassado à carne que chega ao varejo e mercado consumidor.

O abate de vacas de descarte envolve diferentes interesses dentro da cadeia produtiva, caracterizando velhos paradigmas. Com raras exceções, o consumidor possui à sua disposição diferenciação entre carne de vacas e novilhos que é feita no momento da comercialização entre produtores e frigoríficos, beneficiando a comercialização do ponto de vista da indústria. Além disso, o setor industrial baseia a compra de bovinos pelo peso de carcaça, buscando diluição dos custos fixos do abate pelo maior peso de carcaça. Todavia, o aumento do peso de abate demanda maiores custos aos produtores, devido à diminuição da eficiência alimentar dos animais que passam a depositar maior proporção de gordura na carcaça, não levando em consideração as preferências do mercado consumidor. Sendo assim, objetivou-se avaliar as características da carcaça de vacas de descarte da raça Purunã abatidas com diferentes pesos.

\section{MATERIAL E MÉTODOS}

O estudo foi realizado no período de março a julho de 2008. Para tal, 43 vacas de descarte da raça Purunã (1/4 Aberdeen Angus - 1/4 Caracu - 1/4 Charolês - 1/4 Canchim) com idade média inicial de $68,02 \pm 17,36$ meses e condição de escore corporal de 2,78 $\pm 0,18$ foram distribuídas em um delineamento inteiramente ao acaso, com cinco tratamentos (peso de abate): um grupo de animais (controle; $\mathrm{n}=9$ ) foi abatido com peso médio de $401 \mathrm{~kg}$ no início do período de confinamento e, outros quatro grupos, que tiveram pesos de abate inicialmente pretendidos de 430; 460; 490 e $520 \mathrm{~kg}$, foram abatidos com pesos reais de $434(\mathrm{n}=9)$, $461(\mathrm{n}=9), 476(\mathrm{n}=7)$ e $522 \mathrm{~kg}(\mathrm{n}=9)$. O período de confinamento para atingir o peso de abate foi de 30; $51 ; 63$ e 105 dias, respectivamente.

As vacas de descarte oriundas do mesmo lote, anteriormente manejadas em pastagem perene de Hemarthria altíssima cv. Flórida foram confinadas em baias individuais cobertas providas de comedouros e bebedouros. A alimentação foi realizada duas vezes ao dia (08:00 e 14:00 h), permitindo-se sobras de 10\%. O volumoso ofertado à vontade representou $58 \%$ da dieta com base na matéria seca, sendo constituído pela silagem de milho. O concentrado foi fornecido na quantidade de $1,2 \%$ do peso corporal, representando $42 \%$ da dieta, composto por $75 \%$ de grão de milho moído, $23 \%$ de farelo de soja e $2 \%$ de mistura mineral. A dieta continha $10,02 \%$ de proteína bruta, $67,54 \%$ de nutrientes digestíveis totais e $33,40 \%$ de fibra em detergente neutro.

À medida que os lotes chegaram ao peso corporal pretendido foram abatidos em frigorífico comercial de acordo com as normas do SIM após jejum de 14 horas. Após $\mathrm{o}$ abate, as carcaças foram identificadas, divididas ao meio, pesadas para determinação do rendimento de carcaça quente, lavadas e levadas ao resfriamento por 24 horas a $-2^{\circ} \mathrm{C}$. Após $o$ resfriamento foram novamente pesadas para determinar o rendimento de carcaça fria e avaliadas quanto à conformação (1-3: inferior; 4-6: má: 7-9: regular; 10-12: boa; 13-15: muito boa; 16-18: superior), comprimento de carcaça, espessura de coxão e comprimento de perna (MÜLLER, 1987).

Na meia-carcaça direita, foi retirada a secção entre a $10^{\mathrm{a}}$ e $12^{\mathrm{a}}$ costelas, conforme metodologia descrita por Hankins e Howe (1946) e adaptada por Müller (1987), na qual foi medida a espessura de gordura subcutânea e área do Longissimus dorsi. Em seguida, esta secção foi dissecada em músculo, gordura e osso, cujos pesos foram utilizados para estimar suas participações na carcaça, conforme Hankins e Howe (1946).

Os dados foram submetidos à análise de variância, regressão polinomial e correlação de Pearson, adotando-se 5\% como nível de significância (SAS Institute, 2001).

\section{RESULTADOS E DISCUSSÃO}

Os pesos de carcaça quente e fria aumentaram linearmente $(\mathrm{P}<0,05)$ em função da elevação do peso de abate, resultado da maior deposição de tecidos, principalmente músculo e gordura, proporcionado pelo 
aumento do período de alimentação em confinamento (Tabela 1). Considerando que o peso de carcaça é o principal componente da comercialização entre produtores e frigoríficos e que representa o valor comercial dos animais (PASCOAL et al., 2011), deve-se ressaltar que os pesos de carcaça quente obtidos somente superaram o limite mínimo (230 kg) para não penalização do valor da carcaça a partir do abate das vacas com peso corporal estimado de $443 \mathrm{~kg}$. Esses resultados junto com os pré-requisitos de espessura de gordura de cobertura mínimo $(3 \mathrm{~mm})$ exigido pelos frigoríficos servem como balizadores para o abate de fêmeas de descarte da raça utilizada neste experimento.

Kuss et al. (2005a) avaliaram três pesos de abate $(465 ; 507 ; 566 \mathrm{~kg})$ para vacas mestiças CharolêsNelore e verificaram superioridade do peso de carcaça quente e fria somente para os animais abatidos com o maior peso de abate, destacando que o peso de carcaça é determinado pelo peso de abate e rendimento de carcaça. Tal fato foi verificado no presente estudo pela correlação $(\mathrm{P}<0,05)$ do peso de abate com o peso de carcaça quente $(r=0,95)$ e fria $(r=0,96)$ e pela correlação do rendimento de carcaça fria $(\mathrm{P}<0,05)$ com o peso de carcaça quente $(r=0,26)$ e fria $(r=0,34)$. Vale salientar que os pesos de carcaça quente e fria foram correlacionados com o comprimento de carcaça $(r=0,69$ e $r=0,72)$, espessura de coxão $(r=0,78$ e $r=0,79)$, área do Longissimus dorsi $(\mathrm{r}=0,79$ e $\mathrm{r}=0,73)$, espessura de gordura subcutânea $(r=0,63$ e $r=0,65)$, quantidade de músculo $(r=0,92$ e $r=0,95)$ e gordura $(r=0,89$ e $r=0,90)$ da carcaça (Tabela 3). Tais resultados demonstram que o aumento do peso corporal está diretamente associado à deposição de tecidos na carcaça, resultando em aumento de peso, tamanho e conformação da mesma.

Os rendimentos de carcaça quente e fria apresentaram aumento de $0,02 \%$ a cada quilograma a mais no peso de abate (Tabela 1), concordando com os resultados de Restle et al. (2005). Segundo Pascoal et al. (2011) o rendimento de carcaça é influenciado pelo peso corporal e pelo peso do trato gastrintestinal. Vale ressaltar, que o peso corporal determina o rendimento de carcaça, pois à medida que o peso aumenta, ocorre maior deposição de músculo e gordura corporal, contribuindo para o aumento do peso de carcaça em relação ao peso de abate. No presente estudo, tal fato ficou evidente pelas correlações significativas (Tabela 3) do rendimento de carcaça quente e fria com a espessura de coxão ( $r=0,48$ e r =0,37), área do Longissimus dorsi $(\mathrm{r}=0,63$ e $\mathrm{r}=0,40)$ e espessura de gordura subcutânea $(r=0,25$ e $r=0,32)$, além da correlação da espessura de gordura subcutânea e da quantidade de gordura na carcaça $(\mathrm{r}=0,32$ e $\mathrm{r}=0,31)$ com o rendimento de carcaça fria.

Tabela 1 - Características da carcaça de vacas de descarte da raça Purunã abatidas com diferentes pesos

\begin{tabular}{|c|c|c|c|c|c|c|c|c|c|}
\hline \multirow{2}{*}{ Itens } & \multicolumn{5}{|c|}{ Pesos de abate, $\mathrm{kg}$} & \multicolumn{3}{|c|}{ Probabilidade } & \multirow{2}{*}{$\mathrm{R}^{2}$} \\
\hline & 401 & 434 & 461 & 476 & 522 & $\mathrm{~L}$ & $\mathrm{Q}$ & $\mathrm{C}$ & \\
\hline PCQ, kg & 205,16 & 215,48 & 231,35 & 242,32 & 276,42 & 0,001 & 0,668 & 0,663 & 0,49 \\
\hline PCF, kg & 195,04 & 211,01 & 228,26 & 240,85 & 266,47 & 0,001 & 0,551 & 0,646 & 0,50 \\
\hline $\mathrm{RCQ}, \%$ & 50,78 & 49,84 & 50,11 & 51,47 & 51,85 & 0,018 & 0,975 & 0,304 & 0,23 \\
\hline $\mathrm{RCF}, \%$ & 48,51 & 48,78 & 49,44 & 51,15 & 51,00 & 0,013 & 0,106 & 0,092 & 0,24 \\
\hline QR, \% & 1,58 & 2,14 & 1,30 & 1,07 & 1,60 & 0,504 & 0,231 & 0,038 & 0,21 \\
\hline EGS, mm & 1,11 & 2,17 & 3,96 & 3,57 & 4,79 & 0,001 & 0,140 & 0,714 & 0,56 \\
\hline EGS, $\%$ & 0,52 & 1,00 & 1,77 & 1,45 & 1,82 & 0,001 & 0,032 & 0,834 & 0,41 \\
\hline $\mathrm{ALD}, \mathrm{cm}^{2}$ & 58,83 & 53,84 & 57,23 & 58,30 & 70,60 & 0,001 & 0,058 & 0,557 & 0,50 \\
\hline ALD, $\%$ & 30,20 & 25,59 & 25,14 & 24,22 & 26,34 & 0,197 & 0,049 & 0,709 & 0,20 \\
\hline $\mathrm{CC}$, pontos & 8,33 & 9,11 & 8,56 & 9,71 & 12,56 & 0,001 & 0,066 & 0,141 & 0,41 \\
\hline COMP, cm & 130,01 & 130,25 & 135,40 & 135,11 & 136,88 & 0,023 & 0,882 & 0,432 & 0,21 \\
\hline $\mathrm{CP}, \mathrm{cm}$ & 67,78 & 67,50 & 67,50 & 67,00 & 67,61 & 0,853 & 0,693 & 0,838 & -- \\
\hline $\mathrm{EC}, \mathrm{cm}$ & 24,54 & 26,41 & 29,41 & 29,03 & 30,62 & 0,001 & 0,072 & 0,219 & 0,66 \\
\hline
\end{tabular}

Peso de carcaça quente $(P C Q)=-103,52+0,74 x, C V=5,21 ;$ Peso de carcaça fria $(P C F)=-102,35+0,73 x, C V=3,99 ;$ Rendimento de carcaça quente $(\mathrm{RCQ})=41,19+0,02 \mathrm{x}, \mathrm{CV}=4,76$; Rendimento de carcaça fria $(\mathrm{RCF})=41,18+0,02 \mathrm{x}, \mathrm{CV}=3,52$; Quebra ao resfriamento $(\mathrm{QR})=-580+3,85 \mathrm{x}-$ $0,0085 x^{2}+0,0000062 x^{3}, C V=5,43$; Espessura de gordura subcutânea $(E G S, m m)=-11,17+0,032 x, C V=35,85 ; E G S(\%)=-3,1+0,01 x, C V=34,86$; Área do Longisimus dorsi $\left(\mathrm{ALD}, \mathrm{cm}^{2}\right)=-13,105+0,158 \mathrm{x}, \mathrm{CV}=10,45$; ALD $(\%)=441,05-1,76 \mathrm{x}-0,002 \mathrm{x}^{2}, \mathrm{CV}=9,82 ;$ Conformação de carcaça $(\mathrm{CC})=-7,814+0,0379 \mathrm{x}, \mathrm{CV}=16,87$; Comprimento de carcaça $(\mathrm{COMP})=99,876+0,077 \mathrm{x}, \mathrm{CV}=3,99 ; \mathrm{Comprimento} \mathrm{de} \mathrm{perna}(\mathrm{CP})=68,01, \mathrm{CV}=$ 4,22 ; Espessura de coxão $(\mathrm{EC})=1,553+0,058 \mathrm{x}, \mathrm{CV}=6,29 ; \mathrm{L}, \mathrm{Q}$ e C = probabilidade estatística para equação de regressão linear, quadrática e cúbica, respectivamente; $\mathrm{CV}=$ coeficiente de variação; $\mathrm{R}^{2}=$ coeficiente de determinação; $\mathrm{x}=$ peso de abate 
Entretanto, contrariando o exposto por Pascoal et al. (2011), não foi verificado correlação $(\mathrm{P}>0,05)$ do rendimento de carcaça com o peso do trato gastrintestinal vazio, demonstrando que outros fatores foram mais importantes. Estes resultados foram concordantes aos obtidos por Restle, Keplin e Vaz (1997) e Kuss et al. (2009), os quais atribuíram o aumento do rendimento de carcaça ao grau de acabamento mais adiantado em função da maior deposição de gordura na carcaça.

A quebra ao resfriamento apresentou ajuste para equação de regressão cúbica com menor e maior quebra para carcaças de vacas abatidas com 434 e $461 \mathrm{~kg}$ de peso corporal, respectivamente (Tabela 1). A quebra ao resfriamento está intrinsecamente associada às características da carcaça, principalmente com a espessura de gordura de cobertura, a qual protege a carcaça do escurecimento pelo frio e da perda de líquidos por desidratação (MÜLLER, 1987). Por outro lado, Restle, Keplin e Vaz (1997) ponderam que a variação da quebra ao resfriamento pode estar associada a oscilações que ocorrem na câmara fria, como temperatura, velocidade do vento, número de carcaças, os quais podem variar em função da data de abate dos animais, como ocorrido neste estudo. Neste sentido, a quebra ao resfriamento pode apresentar resultados bastante variados, sendo que no presente estudo o peso de abate foi responsável por apenas $21 \%$ da variação. Kuss et al. (2005a) observaram que a quebra ao resfriamento diminuiu com o aumento do peso de abate, resultados atribuídos a maior conformação e espessura de coxão. Todavia, normalmente carcaças com maior grau de acabamento apresentam menores perdas ao resfriamento, sendo que esta característica apresenta correlação negativa com a espessura de gordura subcutânea, como tem se verificado em alguns estudos (ARBOITTE et al., 2004; RESTLE; KEPLIN; VAZ, 1997). No presente estudo, não foi verificado correlação significativa entre as duas características citadas e, da quebra ao resfriamento com as demais.

A espessura de gordura subcutânea apresentou melhor ajuste à equação de regressão linear $(\mathrm{P}<0,05)$, aumentando $0,032 \mathrm{~mm}$ e $0,01 \mathrm{~mm} / 100 \mathrm{~kg}$ de carcaça fria a cada quilograma a mais no peso de abate (Tabela 1), concordando com os resultados obtidos por Arboitte et al. (2004). Segundo Di Marco (1998) a deposição da gordura na carcaça, pela ordem de intensidade de deposição, inicia pela deposição de gordura intermuscular, seguida da gordura subcutânea e, por último, da intramuscular. Considerando o perfil de deposição de gordura na carcaça e, que as vacas encontravam-se magras $(2,78 \pm 0,18 \mathrm{de}$ escore de condição corporal) no início do confinamento, pode-se inferir que a deposição de gordura subcutânea foi mínima nas vacas abatidas com os menores pesos, pois depositavam principalmente gordura intermuscular, a qual segundo Kuss et al. (2005a) influencia a conformação da carcaça. Tais inferências justificam a menor cobertura de gordura e conformação de carcaça das vacas abatidas com menores pesos corporais.

Os resultados de espessura de gordura subcutânea do presente estudo se aproximaram dos verificados por Pacheco et al. (2005) e Missio et al. (2010), os quais demonstraram que o principal fator determinante para o aumento desta característica na carcaça foi o tempo de alimentação em confinamento; superando até mesmo o efeito da concentração energética da dieta como evidenciado na pesquisa de Missio et al. (2010). Vale ressaltar, que a cobertura de gordura subcutânea somente atendeu aos pré-requisitos mínimos dos frigoríficos $(3 \mathrm{~mm})$ com peso de abate estimado de $443 \mathrm{~kg}$. É importante destacar que a espessura de gordura subcutânea foi bem correlacionada $(\mathrm{P}<0,05)$ com a conformação $(\mathrm{r}=0,59)$ e comprimento de carcaça $(r=0,36)$, espessura de coxão $(r=0,73)$ e quantidade de músculo $(\mathrm{r}=0,52)$ e gordura na carcaça $(\mathrm{r}=0,52)$. Essas correlações demonstram que o depósito de gordura na carcaça, principalmente a intermuscular pode atuar pressionando os tecidos da carcaça e assim melhorar a conformação em virtude do aumento do volume muscular e, em menor proporção, o comprimento da carcaça devido ao aumento do volume dos músculos do posterior.

A área do Longissimus dorsi, em $\mathrm{cm}^{2}$, apresentou ajuste à equação de regressão linear $(\mathrm{P}<0,05)$ em função da elevação do peso de abate (Tabela 1 ), resultado do aumento da deposição de músculo $(r=0,76)$ e gordura na carcaça $(r=0,69)$. Quando expressa em função do peso de carcaça fria, a área do Longissimus dorsi apresentou ajuste à equação de regressão quadrática $(\mathrm{P}<0,05)$, com área mínima para o peso de abate de $476 \mathrm{~kg}$. Tais resultados podem estar associados ao perfil de deposição dos tecidos, já que nos menores pesos, o abate ocorreu com baixa deposição de gordura e a área do Longissimus dorsi teve maior participação frente ao peso de carcaça. Por outro lado, com o aumento do peso de abate e deposição de gordura, pode ter ocorrido diminuição da participação da área do Longissimus dorsi em relação ao peso de carcaça. Além disso, deve-se considerar que o aumento da deposição de gordura pode modificar a área específica dos músculos, devido à força física exercida pela gordura sobre as fibras musculares e tecidos da carcaça. Tal fato fica evidente uma vez que a gordura tem deposição mais tardia que o tecido ósseo e muscular (BERG; BUTTERFIELD, 1976). Tais peculiaridades foram evidenciadas pela relação inversa ( $\mathrm{r}=-0,32 ; \mathrm{P}<0,05)$ entre área do Longissimus dorsi expressa em função do peso de carcaça e espessura de gordura subcutânea $(r=-0,32)$ e, pela correlação positiva $(\mathrm{r}=0,52 ; \mathrm{P}<0,05)$ da área do Longissimus dorsi, em $\mathrm{cm}^{2}$, com o marmoreio medido no mesmo músculo.

A área do Longissimus dorsi expressa em relação ao peso de carcaça fria foi negativamente correlacionada 
$(\mathrm{P}<0,05)$ com o peso de carcaça quente $(\mathrm{r}=-0,30)$ e fria $r=-0,42)$, comprimento de carcaça $(r=-0,51)$, espessura de coxão $(r=-0,37)$, quantidade de músculo $(r=-0,32)$ e osso na carcaça $(r=-0,60)$. Estes resultados demonstram que o aumento do peso corporal e consequente deposição de tecidos (músculo, gordura e osso) diminuem a participação desta característica frente ao peso de carcaça (Tabela 3). Além disso, estas correlações indicam a desaceleração da formação do tecido muscular e a intensificação da deposição do tecido adiposo, o que é esperado quando o animal se aproxima do peso adulto (BERG; BUTTERFIELD, 1976). Por outro lado, a área do Longissimus dorsi em $\mathrm{cm}^{2}$ obteve correlação $(\mathrm{P}<0,05)$ com outras características relacionadas à musculosidade da carcaça como a conformação de carcaça $(r=0,72)$ e espessura de coxão $(r=0,54)$, demonstrando que esta variável está diretamente associada à deposição muscular.

O aumento do peso de abate proporcionou elevação linear $(\mathrm{P}>0,05)$ da conformação de carcaça, aumentando 0,0379 pontos a cada quilograma a mais no peso de abate (Tabela 1). Tais resultados são reflexos da recuperação do volume muscular e da deposição da gordura intermuscular e intramuscular com o aumento do período de alimentação. Dentre as características correlacionadas $(\mathrm{P}<0,05)$ com a conformação de carcaça destacaram-se a quantidade de músculo $(\mathrm{r}=0,69)$ e gordura da carcaça $(r=0,75)$, principais responsáveis pela melhora desta característica. Embora a conformação seja uma avaliação subjetiva da expressão muscular da carcaça (MÜLLER, 1987) na qual a gordura subcutânea é desconsiderada, os resultados do presente estudo corroboram com os verificados por Kuss et al. (2005a), os quais citam que o incremento da conformação, em função do aumento do peso de abate, foi causado pela deposição de gordura intermuscular e intramuscular, bem como pelo acúmulo de proteína nos músculos, visto que, os animais estavam em fase de ganho compensatório momento em que, a síntese protéica é superior à degradação. Vale destacar, que além de peso e acabamento da carcaça, os frigoríficos buscam carcaças com boa conformação, já que, a conformação está diretamente associada à quantidade de músculo (carne), principal componente da comercialização entre o varejo e o mercado consumidor.

O comprimento de carcaça respondeu linearmente $(\mathrm{P}<0,05)$ ao aumento do peso de abate, aumentando $0,077 \mathrm{~cm}$ a cada quilograma a mais no peso de abate (Tabela 1). O comprimento de carcaça foi correlacionado $(\mathrm{P}<0,05)$ com a espessura de gordura subcutânea $(\mathrm{r}=0,36)$, marmoreio $(\mathrm{r}=0,35)$, quantidade de músculo $(r=0,59)$, gordura $(r=0,63)$, osso $(\mathrm{r}=0,67)$ na carcaça, área do Longissimus dorsi $(\mathrm{r}=0,41)$, espessura de coxão $(\mathrm{r}=0,45)$ e conformação $(\mathrm{r}=0,31)$, demonstrando que esta característica está diretamente associada à deposição de tecidos (músculo, gordura e osso) na carcaça (Tabela 3). Corroborando, Kuss et al. (2005a) atribuíram o aumento do comprimento da carcaça de vacas de descarte à pressão entre costelas causada pelo aumento de gordura inter e intramuscular na região do costilhar com o aumento do peso de abate.

O comprimento de perna não foi alterado $(\mathrm{P}<0,05)$ pelo peso de abate (Tabela 1), tampouco correlacionado $(\mathrm{P}>0,05)$ com nenhuma característica estudada. Em contraste, a espessura de coxão respondeu linearmente ao aumento do peso de abate, aumentando $0,058 \mathrm{~cm}$ a cada quilograma a mais no peso de abate, resultado do acúmulo muscular $(\mathrm{r}=0,76)$ e deposição de gordura na carcaça $(r=0,73)$, em virtude do maior período de alimentação dos animais experimentais.

A quantidade absoluta de músculo na carcaça respondeu linearmente ao peso de abate, aumentando $0,30 \mathrm{~kg}$ a cada quilograma a mais no peso de abate (Tabela 2). Quando expressa em percentagem, a quantidade de músculo na carcaça diminuiu em função do peso de abate, consequência do aumento percentual de gordura na carcaça, concordando com os resultados verificados por Kuss et al. (2005b). Segundo Berg e Butterfield (1976) a deposição muscular diminuiu à medida que se inicia a fase de deposição de gordura, fato que normalmente está associado a animais em crescimento, situação contrária ao do presente estudo.

A quantidade de gordura na carcaça aumentou linearmente em função do peso de abate (Tabela 2), determinando diminuição da proporção de músculo em relação à gordura nos maiores pesos de abate. Estes resultados concordam com o exposto por Berg e Butterfield (1976), os quais citam que a gordura aumenta com o avanço do peso corporal, apresentando maior desenvolvimento com idade mais avançada do animal.

O aumento excessivo da gordura na carcaça, como o ocorrido nos maiores pesos de abate do presente estudo, não representa remuneração ao produtor, já que é recortada da carcaça antes do registro de seu peso, afetando negativamente o peso de carcaça. Além disso, é sabido que a quantidade de tecido adiposo depositado no corpo do animal determina sua eficiência alimentar, pois, em comparação com o tecido muscular, requer 2,25 vezes mais energia para sua deposição, onerando o processo produtivo.

Os aspectos mencionados contribuem para a marginalização do preço pago pela carcaça de vacas de descarte em relação ao pago pela carcaça de novilhos. Tal circunstância está associada, muitas vezes, ao fato de fêmeas produzirem maior quantidade de gordura de descarte que novilhos (CATTELAM et al., 2010; PAULINO et al., 2009). Considerando o exposto, é possível afirmar que o aumento do peso de abate além 
Tabela 2 - Composição da carcaça de vacas de descarte da raça Purunã abatidas com diferentes pesos

\begin{tabular}{|c|c|c|c|c|c|c|c|c|c|}
\hline \multirow{2}{*}{ Itens } & \multicolumn{5}{|c|}{ Pesos de abate, $\mathrm{kg}$} & \multicolumn{3}{|c|}{ Probabilidade } & \multirow{2}{*}{$\mathrm{R}^{2}$} \\
\hline & 401 & 434 & 461 & 476 & 522 & $\mathrm{~L}$ & $\mathrm{Q}$ & $\mathrm{C}$ & \\
\hline $\mathrm{M}, \mathrm{kg}$ & 130,24 & 139,06 & 143,87 & 149,89 & 165,36 & 0,001 & 0,989 & 0,415 & 0,45 \\
\hline $\mathrm{M}, \%$ & 66,82 & 65,97 & 63,00 & 62,39 & 62,30 & 0,001 & 0,367 & 0,132 & 0,54 \\
\hline $\mathrm{G}, \mathrm{kg}$ & 29,04 & 35,89 & 46,44 & 46,45 & 62,40 & 0,001 & 0,540 & 0,932 & 0,75 \\
\hline $\mathrm{G}, \%$ & 14,72 & 16,83 & 20,31 & 19,16 & 23,34 & 0,001 & 0,041 & 0,759 & 0,74 \\
\hline $\mathrm{O}, \mathrm{kg}$ & 35,04 & 35,79 & 37,66 & 43,18 & 39,52 & 0,005 & 0,887 & 0,353 & 0,28 \\
\hline $\mathrm{O}, \%$ & 18,06 & 17,05 & 16,56 & 17,91 & 14,72 & 0,001 & 0,269 & 0,079 & 0,35 \\
\hline $\mathrm{M} / \mathrm{O}$ & 3,76 & 3,88 & 3,83 & 3,51 & 4,49 & 0,321 & 0,785 & 0,092 & -- \\
\hline $\mathrm{M}+\mathrm{G} / \mathrm{O}$ & 4,61 & 4,88 & 5,06 & 4,60 & 6,18 & 0,001 & 0,481 & 0,114 & 0,34 \\
\hline
\end{tabular}

Músculo $(\mathrm{M}, \mathrm{kg})=-7,07+0,30 \mathrm{x}+0,21 \mathrm{ID}, \mathrm{CV}=6,48 ; \mathrm{M}(\%)=88,05-0,053 \mathrm{x}, \mathrm{CV}=4,16 ;$ Gordura $(\mathrm{G}, \mathrm{kg})=-104,94+0,33 \mathrm{x}, \mathrm{CV}=12,47 ; \mathrm{G}(\%)$ $=-18,47+0,082 x, \mathrm{CV}=12,96 ;$ Osso $(\mathrm{O}, \mathrm{kg})=7,32+0,069 \mathrm{x}, \mathrm{CV}=11,15 ; \mathrm{O}(\%)=28,125-0,024 \mathrm{x}, \mathrm{CV}=11,50 ; \mathrm{Relação} \mathrm{M} / \mathrm{O}=2,91, \mathrm{CV}=21,34$; Porção comestível $(\mathrm{M}+\mathrm{G} / \mathrm{O})=1,135+0,008 \mathrm{x}, \mathrm{CV}=22,50 ; \mathrm{L}, \mathrm{Q}$ e C = probabilidade estatística para equação de regressão linear, quadrática e cúbica, respectivamente; $\mathrm{CV}=$ coeficiente de variação; $\mathrm{R}^{2}=$ coeficiente de determinação; $\mathrm{x}=$ peso de abate; $\mathrm{ID}=$ idade inicial

das exigências mínimas dos frigoríficos determina menor lucratividade ao produtor rural, principalmente quando o mercado desfavorece a comercialização da carne bovina entre produtores e indústria.

A quantidade de osso na carcaça aumentou $0,069 \mathrm{~kg}$ a cada quilograma a mais no peso de abate (Tabela 2). Já a percentagem de osso na carcaça diminuiu $0,024 \%$ a cada quilograma a mais no peso de abate, reflexo do aumento de gordura na carcaça, concordando com os resultados Kuss et al. (2005a). Segundo Berg e Butterfield (1976) o tecido ósseo tem seu maior impulso de crescimento no estágio mais jovem do animal, ao passo que o muscular em um estágio intermediário e o adiposo em estágio de desenvolvimento mais avançado. Restle et al. (2001) avaliando a carcaça de vacas de descarte abatidas com diferentes idades $(4 ; 5-6 ; 7-8,+8$ anos) verificaram que os animais cessaram seu crescimento ao atingirem 7 anos de idade, fato verificado pela estabilização do peso e tamanho de carcaça. Todavia, considerando a idade dos animais deste estudo não se esperava que a quantidade absoluta de osso fosse alterada, devido ao curto período de alimentação. Deve-se considerar que durante a gestação e lactação as vacas do presente estudo foram manejadas em pastagem de média/baixa qualidade, o que possivelmente determinou mobilização de minerais ósseos em virtude da elevada demanda por nutrientes, situação que provavelmente foi revertida durante o período de alimentação em confinamento. Tais suposições são compatíveis às evidências de Wu et al. (2001), onde fêmeas ao final da gestação e início da lactação não são capazes de atender às demandas de $\mathrm{Ca}$ e $\mathrm{P}$ pelas dietas normalmente ofertadas, gerando um déficit de minerais que seria compensado pela mobilização das reservas ósseas. Portanto, a taxa de reabsorção do osso, nestes casos, aumentaria até metade da lactação, ponto a partir do qual a reabsorção é reduzida e ocorre elevação da deposição de $\mathrm{Ca}$ e $\mathrm{P}$, restabelecendo as reservas ósseas.

A porção comestível da carcaça é representada por músculo e gordura, sendo a maior proporção de músculo de interesse para a maioria dos segmentos da cadeia produtiva, embora a gordura apresente relevante importância sobre as características de qualidade da carcaça e da carne (MÜLLER, 1987) e sobre o peso de carcaça. Nesse sentido, verificou-se que a relação entre músculo e osso não foi alterada $(\mathrm{P}>0,05)$ pelo peso de abate, visto que, embora tenha ocorrido aumento da quantidade absoluta de músculo na carcaça, ocorreu também aumento da quantidade absoluta de osso (Tabela 2). Por outro lado, quando somado a quantidade de gordura na carcaça à quantidade de músculo, verificou-se que o aumento do peso de abate proporcionou elevação linear $(\mathrm{P}<0,05)$ na porção comestível (músculo + gordura/ osso), aumentando $0,008 \%$ a cada quilograma a mais no peso de abate.

O somatório das percentagens dos três tecidos (músculo, gordura e osso) na carcaça sempre será $100 \%$. Portanto, a elevação da percentagem de um tecido implica em decréscimo da percentagem de outro. Portanto, em valores absolutos todos os tecidos aumentaram, mas em valores relativos, a gordura aumentou e a quantidade de músculo e osso diminuiu, sendo a quantidade destes tecidos bem correlacionada $(\mathrm{P}<0,05)$ com as características quantitativas e métricas da carcaça (Tabela 3). Tais resultados demonstram a importância da deposição dos tecidos corporais, principalmente músculo e gordura, para aumento de peso, musculosidade 
Tabela 3 - Matriz de correlação para as principais características da carcaça de vacas de descarte da raça Purunã abatidas com diferentes pesos

\begin{tabular}{|c|c|c|c|c|c|c|c|c|c|c|c|c|c|}
\hline & & PCQ & PCF & RCQ & $\mathrm{RCF}$ & $\mathrm{PC}$ & EGS & ALD & $\mathrm{CC}$ & $\mathrm{COM}$ & $\mathrm{EC}$ & $\mathrm{M}$ & $\mathrm{G}$ \\
\hline \multirow{2}{*}{ PCF } & $r$ & 0,96 & & & & & & & & & & & \\
\hline & $\mathrm{P}$ & $* * *$ & & & & & & & & & & & \\
\hline \multirow{2}{*}{ RCQ } & $\mathrm{r}$ & 0,48 & 0,32 & & & & & & & & & & \\
\hline & $\mathrm{P}$ & $* *$ & $*$ & & & & & & & & & & \\
\hline \multirow{2}{*}{$\mathrm{RCF}$} & $\mathrm{r}$ & 0,26 & 0,34 & 0,61 & & & & & & & & & \\
\hline & $\mathrm{P}$ & $*$ & $*$ & $* * *$ & & & & & & & & & \\
\hline \multirow{2}{*}{ EGS } & $\mathrm{r}$ & 0,63 & 0,65 & 0,25 & 0,32 & 0,47 & & & & & & & \\
\hline & $\mathrm{P}$ & $* * *$ & $* * *$ & ns & $*$ & $* *$ & & & & & & & \\
\hline \multirow{2}{*}{ ALD } & $\mathrm{r}$ & 0,79 & 0,73 & 0,63 & 0,40 & 0,37 & 0,46 & & & & & & \\
\hline & $\mathrm{P}$ & $* * *$ & $* * *$ & $* * *$ & $* *$ & $* *$ & $* *$ & & & & & & \\
\hline \multirow{2}{*}{$\mathrm{CC}$} & $\mathrm{r}$ & 0,71 & 0,71 & 0,53 & 0,51 & 0,43 & 0,59 & 0,72 & & & & & \\
\hline & $\mathrm{P}$ & $* * *$ & $* * *$ & $* *$ & $* *$ & $* *$ & $* * *$ & $* * *$ & & & & & \\
\hline \multirow{2}{*}{$\mathrm{COM}$} & $r$ & 0,69 & 0,72 & 0,01 & $-0,04$ & $-0,05$ & 0,36 & 0,41 & 0,31 & & & & \\
\hline & $\mathrm{P}$ & $* * *$ & $* * *$ & ns & ns & ns & $*$ & $* *$ & $*$ & & & & \\
\hline \multirow{2}{*}{$\mathrm{EC}$} & $\mathrm{r}$ & 0,78 & 0,79 & 0,48 & 0,37 & 0,31 & 0,73 & 0,54 & 0,68 & 0,45 & & & \\
\hline & $\mathrm{P}$ & $* * *$ & $* * *$ & $* *$ & $*$ & $*$ & $* * *$ & $* * *$ & $* * *$ & $*$ & & & \\
\hline \multirow{2}{*}{ M } & $\mathrm{r}$ & 0,92 & 0,95 & 0,37 & 0,39 & 0,30 & 0,52 & 0,76 & 0,69 & 0,64 & 0,73 & & \\
\hline & $\mathrm{P}$ & $* * *$ & $* * *$ & $*$ & $* *$ & $\mathrm{~ns}$ & $* *$ & $* * *$ & $* * *$ & $* * *$ & $* * *$ & & \\
\hline \multirow{2}{*}{ G } & $\mathrm{r}$ & 0,89 & 0,90 & 0,35 & 0,28 & 0,38 & 0,83 & 0,69 & 0,75 & 0,63 & 0,81 & 0,77 & \\
\hline & $\mathrm{P}$ & $* * *$ & $* * *$ & $* *$ & $* *$ & $*$ & $* * *$ & $* * *$ & $* * *$ & $* * *$ & $* * *$ & $* * *$ & \\
\hline \multirow{2}{*}{$\mathrm{O}$} & $r$ & 0,63 & 0,70 & $-0,04$ & 0,10 & $-0,51$ & 0,11 & 0,26 & 0,25 & 0,67 & 0,39 & 0,59 & 0,47 \\
\hline & $\mathrm{P}$ & $* * *$ & $* * *$ & ns & ns & $* *$ & ns & ns & ns & $* * *$ & $* *$ & $* * *$ & $* *$ \\
\hline
\end{tabular}

$\mathrm{PCQ}=$ peso de carcaça quente, $\mathrm{PCF}=$ peso de carcaça fria, $\mathrm{RCQ}=$ rendimento de carcaça quente, $\mathrm{RCF}=$ rendimento de carcaça fria, $\mathrm{PC}=$ porção comestível, EGS = espessura de gordura subcutânea, $\mathrm{ALD}=$ área do Longisimus dorsi, $\mathrm{CC}=$ conformação da carcaça, $\mathrm{COM}=$ comprimento de carcaça, $\mathrm{CP}=$ comprimento de perna, $\mathrm{EC}=$ espessura de coxão, $\mathrm{M}=$ quantidade absoluta de músculo na carcaça, $\mathrm{G}=$ quantidade absoluta de gordura na carcaça e $\mathrm{O}=$ quantidade absoluta de osso na carcaça; $* \mathrm{P}<0,05 ; * * \mathrm{P}<0,01 ; * \mathrm{P}<0,0001$; ${ }^{\text {ns }}=$ não significativo

e acabamento da carcaça de vacas de descarte, proporcionando carcaças com melhor conformação e qualidade. De modo geral, as elevadas correlações entre os tecidos da carcaça, demonstram que em vacas de descarte ocorre concomitante deposição de músculo, gordura e osso (valores absolutos) com aumento do peso corporal, quantitativamente nesta ordem, em virtude da necessidade de recuperar o estado corporal ocasionado pelo período de alta demanda (gestação e lactação) e baixa oferta de nutrientes provenientes do pasto.

\section{CONCLUSÃO}

Para o sistema de produção, considerando o atual método de remuneração, o peso de abate de vacas de descarte não deve exceder as exigências mínimas dos frigoríficos, tendo em vista a redução da eficiência alimentar com o avanço da deposição de gordura corporal.

\section{REFERÊNCIAS}

ANUÁRIO estatístico da produção animal. São Paulo: Prol Editora Gráfica, 2010. 360 p.

ARBOITTE, M. Z. et al. Características da carcaça de novilhos 5/8 Nelore - 3/8 Charolês abatidos em diferentes estádios de desenvolvimento. Revista Brasileira de Zootecnia, v. 33, n. 4, p. 969-977, 2004.

BERG, R. T.; BUTTERFIELD, R. M. New concepts of cattle growth. New York: Sidney University, 1976. 240p. 
CATTELAM, J. et al. Gorduras de descarte e componentes externos do corpo de novilhos e vacas de descarte de diferentes grupos genéticos. Ciência Rural, v. 40, n. 12, p. 2541-2548, 2010.

CATTELAM, J. et al. Composição física da carcaça e qualidade da carne de novilhos e vacas de descarte de diferentes grupos genéticos submetidos a diferentes frequências de alimentação. Ciência Animal Brasileira, v. 10 , n. 3, p. 764-775, 2009 .

DI MARCO, O. N. Crescimiento de vacunos para carne. Mar Del Plata, 1998. 246 p.

FERREIRA, J. J. et al. Características de carcaça de vacas de descarte e novilhos mestiços Charolês $\times$ Nelore em confinamento sob diferentes frequências de alimentação. Revista Brasileira de Zootecnia, v. 38, n. 10, p. 1974-1982, 2009.

HANKINS, O. G.; HOWE, P. E. Estimation of the composition of beef carcass and cuts. Washington: Unite State Department of Agriculture, 1946. (Technical Bulletin, 926).

KUSS, F. et al. Características da carcaça de vacas de descarte terminadas em confinamento recebendo dietas com ou sem adição de monensina. Ciência Animal Brasileira, v. 10, n. 1, p. 83-90, 2009.

KUSS, F. et al. Características da carcaça de vacas de descarte de diferentes grupos genéticos terminadas em confinamento com distintos pesos. Revista Brasileira de Zootecnia, v. 34, n. 3, p. 915-925, 2005a.

KUSS, F. et al. Composição física da carcaça e qualidade da carne de vacas de descarte de diferentes grupos genéticos terminadas em confinamento com distintos pesos. Revista Brasileira de Zootecnia, v. 34, n. 4, p. 1285-1296, 2005 b.

MISSIO, R. L. et al. Características da carcaça e da carne de tourinhos terminados em confinamento, recebendo diferentes níveis de concentrado na dieta. Revista Brasileira de Zootecnia, v. 39, n. 7, p. 1610-1617, 2010.

MÜLLER, L. Normas para avaliação de carcaças e concurso de carcaças de novilhos. 2 ed. Santa Maria: UFSM, $1987.31 \mathrm{p}$.
PACHECO, P. S. et al. Características quantitativas da carcaça de novilhos jovens e superjovens de diferentes grupos genéticos. Revista Brasileira de Zootecnia, v. 34, n. 5, p. 1666-1677, 2005.

PASCOAL, L. L. et al. Relações comerciais entre produtor, indústria e varejo e as implicações na diferenciação e precificação de carne e produtos não-carcaça. Revista Brasileira de Zootecnia, v. 40, p. 82-92, 2011. Suplemento.

PASCOAL, L. L. et al. Meat yield of culled cow and steer carcasses. Revista Brasileira de Zootecnia, v. 38, n. 11, p. 2230-2237, 2009.

RESTLE, J. et al. Características das partes não-integrantes da carcaça de novilhos 5/8 Nelore 3/8 Charolês abatidos em três estádios de desenvolvimento. Revista Brasileira de Zootecnia, v. 34, n. 4, p. 1339-1348, 2005.

RESTLE, J. et al. Efeito da Suplementação energética sobre a carcaça de vacas de diferentes idades, terminadas em pastagem cultivada de estação fria sob pastejo horário. Revista Brasileira de Zootecnia, v. 30, n. 3, p. 1076-1083, 2001. Suplemento 1.

RESTLE, J.; KEPLIN, L. A. S.; VAZ, F. N. Características da carcaça de novilhos Charolês, abatidos com diferentes pesos. Pesquisa Agropecuária Brasileira, v. 32, n. 8, p. 851-856, 1997.

SAS Institute. Statistical analysis system user's guide. Version 8.02. Cary: Statistical Analysis System Institute, 2001.

PAUlinO, P. V. R. et al. Deposição de tecidos e componentes químicos corporais em bovinos Nelore de diferentes classes sexuais. Revista Brasileira de Zootecnia, v. 38, n. 12, p. 2516-2524, 2009.

VAZ, F. N. et al. Características de carcaça e da carne de novilhos e novilhas braford superjovens, terminados com suplementação em pastagem cultivada. Ciência Animal Brasileira, v. 11, n. 1, p. 42-52, 2010.

WU, Z. et al. Milk production, estimated phosphorus excretion, and bone characteristics of dairy cows fed different amounts of phosphorus for two or three years. Journal of Dairy Science, v. 84, n. 7, p. 1738-1748, 2001. 